

\title{
CHARACTERIZATION OF SHALES USING Ti-T2 NMR MAPS
}

\author{
Marc Fleury, Maria-Fernanda Romero-Sarmiento
}

\section{To cite this version:}

Marc Fleury, Maria-Fernanda Romero-Sarmiento. CHARACTERIZATION OF SHALES USING Ti-T2 NMR MAPS. Journal of Petroleum Science and Engineering, 2016, 137, pp.55-62. 10.1016/j.petrol.2015.11.006 . hal-01258768

\section{HAL Id: hal-01258768 https://hal.science/hal-01258768}

Submitted on 19 Jan 2016

HAL is a multi-disciplinary open access archive for the deposit and dissemination of scientific research documents, whether they are published or not. The documents may come from teaching and research institutions in France or abroad, or from public or private research centers.
L'archive ouverte pluridisciplinaire HAL, est destinée au dépôt et à la diffusion de documents scientifiques de niveau recherche, publiés ou non, émanant des établissements d'enseignement et de recherche français ou étrangers, des laboratoires publics ou privés. 


\title{
CHARACTERIZATION OF SHALES USING $T_{1}-T_{2}$ NMR MAPS
}

$$
\text { By }
$$

Marc Fleury and Maria Romero-Sarmiento

IFP Energies nouvelles, 1 avenue de Bois-Préau, 92852 Rueil-Malmaison, France.

\author{
Email : marc.fleury@ifpen.fr
}

Keywords: NMR, T1-T2 map, shale, methane, kerogen, diffusivity, tortuosity

For review only 


\begin{abstract}
Nuclear Magnetic Resonance (NMR) relaxation methods are key techniques for evaluating shales, both from cores and logging data. First, very small pore sizes, down to nano-meter length scales, can be detected and quantified if the NMR tool has the ability to measure relaxation times in the range $[0.1-1 \mathrm{~ms}]$, and second the different proton populations (water, oil, gas, kerogen) can be distinguished using $2 \mathrm{D} \mathrm{T}_{1}-\mathrm{T}_{2}$ maps. We use a NMR instrument working at a higher frequency $(23 \mathrm{MHz})$ that yields a much higher sensitivity than standard plug-size benchtop apparatus. In this work, we show the position of each proton population in this map: hydroxyls from the clay $\left(\mathrm{T}_{2}<0.1 \mathrm{~ms}\right.$, $\left.10<T_{1} / T_{2}<100\right)$, water $\left(T_{1} / T_{2} \sim 2\right)$, and in certain situations kerogen $\left(10<T_{1} / T_{2}<100\right)$. Methane can be clearly distinguished with $T_{1} / T_{2} \sim 10$. One can use the $T_{1} / T_{2}$ contrast to separate the different contributions. As an additional characterization, deuterium tracer techniques are used to quantify the connectivity of the pore network system, providing a measure of tortuosity. Due to high diffusivity, the $T_{2}$ distribution is affected by diffusive pore coupling and therefore, pores smaller than about $800 \mathrm{~nm}$ are theoretically all gathered at a single relaxation time.
\end{abstract}




\section{INTRODUCTION}

The characterization of gas shales remains a challenge and cannot be performed using conventional petrophysical techniques. Even for basic properties such as porosity and permeability, specialized protocols and instrumentation are required. Standard measurement of pore sizes as well as advanced microscopic techniques (e.g. Scanning Electronic Microscopy coupled with Focused Ion Beam) have shown the existence of very small pores down to the nanometer scale [1,2]. In this context, NMR relaxation techniques are very appropriate because small quantity of water or gas can be detected in such small pore sizes. For example in smectites having sheet-like pores, it is possible with an appropriate NMR instrument to detect and quantify the interlayer water content even when the pore width is only one or two water layers thick [3]. In such model systems, simple 1D NMR measurement are sufficient. However, for complex porous media such as shales, standard $\mathrm{T}_{2}$ relaxation time distributions provide limited information [4]. Indeed, there is a potential overlapping of the signature of the different proton populations originating from water, oil or gas and organic matter. Multidimensional NMR techniques give clearly much more possibilities for separating the different proton contributions [5-7]. The first well known technique used in

conventional hydrocarbon systems is to use the diffusion contrast between liquids and/or gas in a D- $\mathrm{T}_{2}$ map [8]. However, in shales, it has various advantages and drawbacks [7]. Another method is to use the $T_{1} / T_{2}$ contrast originating from the different intra and intermolecular NMR interactions $[5,9,10]$. Recently, this contrast (i.e. $T_{1}-T_{2}$ maps) has been used in conjunction with geochemical data [11]. We develop this approach in the present work and propose to locate all proton populations in a $T_{1}-T_{2}$ map at different saturation conditions

We first recall the NMR relaxation theory for different proton populations in the context of nano-porous media, for liquid, gas, and also for solids. The NMR instrument and the methane high pressure cell are then described. In order to identify the different signatures, we studied kerogen isolated from different shales, and shales in different saturation states. We finally propose a $T_{1}-T_{2}$ fluid mapping based on our observations.

\section{NMR THEORY}

\subsection{Relaxation of water in nanoporous media}

For water in porous media, the dominant relaxation process is the result of interactions between the spins carried by molecules exploring the pore space by diffusion, and the electronic spins at the solid surface [12]. These interactions are effective only close to the surface in a layer of thickness $\varepsilon_{S}(<0.5 \mathrm{~nm})$ and are characterized by a decay time constant $T_{S}$ (i.e. a spin carried by a molecule diffusing only at the solid surface will be characterized by the relaxation time $\mathrm{T}_{\mathrm{S}}$ ). Similarly, far from the surface, the intra and inter-molecular interactions produce a much longer decay time constant $\mathrm{T}_{\mathrm{B}}$. In a pore, let 
us define two regions: a bulk volume with a volume fraction $f_{b}$, and a surface layer with a volume fraction $f_{s}\left(f_{b}+f_{s}=1\right)$. Due to molecular diffusion, there is an exchange between the surface and bulk volumes with a typical exchange time $\tau_{e x}$. In the so-called fast exchange regime $\left(\tau_{e x}<<T\right)$ or fast diffusion regime, the measured relaxation rate $1 / T$ is an average of the bulk and surface relaxation rates weighted by the volume fraction:

$$
\frac{1}{T_{2}}=\frac{f_{s}}{T_{2 s}}+\frac{f_{B}}{T_{2 B}} \approx \frac{S_{p}}{V_{p}} \frac{\varepsilon_{S}}{T_{2 s}}+\frac{1}{T_{2 B}}
$$

We show here the transverse relaxation time $T_{2}$ but the equation is also valid for the longitudinal relaxation $T_{1}$. The above equation yields the well-known dependence with the surface to volume ratio $(S p / V p)$ of a single (closed) pore (Figure 1). Note here that we neglect an additional gradient term. The strength of interactions with the solid is usually expressed as the surface relaxivity $\rho_{2}$ or relaxation velocity at the pore surface defined as $\rho_{2}=\varepsilon_{S} / T_{2 S}$. Using typical values of surface relaxivities between 1 and $10 \mu \mathrm{m} / \mathrm{s}$, the relaxation time of water located in a sheet-like pore of thickness $1 \mathrm{~nm}$ for example (hence $\mathrm{V} / \mathrm{S}=1 \mathrm{~nm}$ ) will be in the range 0.1 to $1 \mathrm{~ms}$. Such values are easily accessible to most commercial spectrometers and to some in-situ logging instruments. Therefore, NMR has the capability for detecting and quantifying the mass of water present in very small pores. However, there are two important issues. First, in nanopores, the measured relaxation time may not give an indication of the pore size (or thickness for a sheet) according to equation 1 because the length scale of the NMR interactions are comparable to the thickness (a few nanometer compared to $\varepsilon_{S} \sim 0.5 \mathrm{~nm}$ ). This is indeed the case in the interlayer space of smectites [3] in which equation 1 has been found not to be valid. Second, the diffusive exchange between pores [13] may lead to a $T_{2}$ distribution that does not represent anymore a pore size distribution (a distribution of $\mathrm{V} / \mathrm{S}$ ) but an average volume to an average surface ratio. We will discuss this effect further when presenting diffusion experiments on a sample. Note also that a consequence of the fast exchange model described above is that the measured relaxation time cannot be smaller than $T_{2 S}$ Hence, if smaller values are detected, an another model must be used.

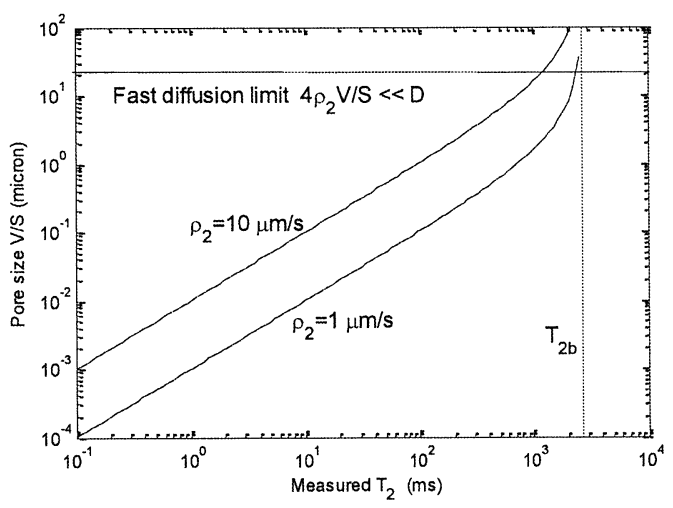

Figure 1: Graphical representation of equation 1 with two surface relaxivities covering the range of usual values. 


\subsection{Relaxation of pseudo-solid material}

Very short relaxation times $\left(<0.1 \mathrm{~ms}\right.$ or less than $\left.\mathrm{T}_{2 \mathrm{~S}}\right)$ are produced by processes related to the mobility of protons. The theoretical framework is the so-called BloembergenPurcell-Pound (BPP) model [14] relating the longitudinal and transverse relaxation times to the correlation time $\tau$ of the dipolar interactions:

$$
\begin{aligned}
& \frac{1}{T_{1}}=2 C\left[\frac{2 \tau}{1+\omega^{2} \tau^{2}}+\frac{8 \tau}{1+4 \omega^{2} \tau^{2}}\right] \\
& \frac{1}{T_{2}}=C\left[6 \tau+\frac{10 \tau}{1+\omega^{2} \tau^{2}}+\frac{4 \tau}{1+4 \omega^{2} \tau^{2}}\right]
\end{aligned}
$$

where $\omega$ is the Larmor frequency and $C$ is a constant. A single value of correlation time $\tau$ is assumed here for simplicity. For fast isotropic molecular tumbling, as is the case in the above mentioned fast diffusion model, $\omega \tau \ll<1$ and $\mathrm{T}_{1} / \mathrm{T}_{2}=1$ (in fact, due to the heteronuclear dipole-dipole interactions with the electronic spins, we have $T_{1} / T_{2} \sim 2$ ). When molecules are not mobile, the correlation time is several orders of magnitude larger, $\omega \tau>>1$, and the ratio $\mathrm{T}_{1} / \mathrm{T}_{2} \sim \omega^{2} \tau^{2}$ is much larger than 1 and depends on the Larmor frequency. For example for ice, $T_{1}=70 \mathrm{~s}$ and $\mathrm{T}_{2}=8 \mu \mathrm{s}$ at $30 \mathrm{MHz}$ [15]. A large $\mathrm{T}_{1} / \mathrm{T}_{2}$ ratio is seen in many materials of interest for the petroleum industry: heavy oil, coal, organic matter.

\subsection{Relaxation of methane}

For bulk methane in the gas phase (i.e. at temperature of interest here), the longitudinal and transverse relaxation mechanisms are dominated by spin rotation [16], in contrast with intra and intermolecular interaction occurring in simple liquids (or in liquid methane). $T_{1}$ and $T_{2}$ are still equal and governed by equation 2 , but they increase with pressure and are in the range [500-5000 ms] for methane pressure between 25 up to 200 bar. More interestingly in rock core materials [17] or for adsorbed gas in nanoporous material [18] at low temperature $(100 \mathrm{~K})$, the $T_{1} / T_{2}$ ratio of methane increases considerably ( $\sim 10$ or more). This is due to anisotropic rotational motions at the surface, with the existence of two correlation times. $T_{1}$ will then be sensitive to the fast correlation time, while $\mathrm{T}_{2}$ to the slow one. In a partially saturated porous media, relaxation of methane still occurs although weaker despite water wetting the surface [17].

\section{MATERIALS AND NMR METHODS}

\subsection{NMR methods}

The experiments have been carried out on a Maran Ultra proton spectrometer from Oxford Instruments with a proton Larmor frequency of $23.7 \mathrm{MHz}$. Standard free induction decay (FID) and transverse magnetization CPMG decay curves were measured. When needed, we used a modified CPMG sequence in which the inter-echo time is initially set at the lowest possible and then increased gradually up to $100 \mu$ s or more in 
order to catch at the same time very short and very long relaxation times. $2 \mathrm{D} \mathrm{T}_{1}-\mathrm{T}_{2}$ maps were determined using an inversion recovery sequence followed by a CPMG sequence:

$$
\mathrm{P}_{180}-\tau_{1}-\mathrm{P}_{90}-\left(\tau-\mathrm{P}_{180} \text { - echo- }\right)_{\mathrm{n}}
$$

where $\tau_{1}$ takes usually 40 discrete values spaced logarithmically, and the number of echo $\mathrm{n}$ is adjusted in order to reach zero signal (noise level). Hence, we obtain a magnetization function of two times, $\tau_{1}$ and $n \tau$, later analyzed in terms of a $T_{1}-T_{2} 2 D$ map computed with an in-house 2D inverse Laplace transform software.

Table 1: Main characteristics of the NMR instrument. $\mathrm{P} 90$ is the $90^{\circ}$ pulse duration.

\begin{tabular}{|c|c|c|c|c|c|}
\hline $\begin{array}{l}\text { Probe diameter } \\
(\mathrm{mm})\end{array}$ & $\begin{array}{c}\text { Probe dead } \\
\text { time } \\
(\mu \mathrm{s})\end{array}$ & $\begin{array}{l}\text { P90 } \\
(\mu \mathrm{s})\end{array}$ & $\begin{array}{c}\text { Filter dead time } \\
100 \mathrm{kHz} / 1 \mathrm{MHz} \\
(\mu \mathrm{s})\end{array}$ & $\begin{array}{c}\tau \text { spacing } \\
(\mu \mathrm{s})\end{array}$ & $\begin{array}{c}1^{\text {st }} \text { FID } \\
(\mu \mathrm{s})\end{array}$ \\
\hline \multirow[t]{2}{*}{10} & \multirow[t]{2}{*}{5} & \multirow[t]{2}{*}{2} & 15 & 25 & 21 \\
\hline & & & 5 & 15 & 11 \\
\hline 18 & 15 & 6 & 15 & 30 & 33 \\
\hline
\end{tabular}

We used two NMR probes of diameter 10 and $18 \mathrm{~mm}$ depending on the desired information and size of samples. The capacity of detecting "solid like protons" with very short relaxation times depends critically on the probe dead time. Using a small probe diameter of $10 \mathrm{~mm}$ reduces significantly the dead time down to $5 \mu \mathrm{s}$ compared to the standard $18 \mathrm{~mm}$ probe (Table 1). It also reduces the $90^{\circ}$ pulse duration to insure a larger frequency bandwidth when detecting solid protons. In addition, the filter dead time can be reduced significantly using a $1 \mathrm{MHz}$ bandwidth, at the expenses however of the signal to noise ratio. Note that the smallest $\tau$ spacing available is $15 \mu$ s and hence, the first acquired point in the CPMG decay is at $30 \mu \mathrm{s}$.

For diffusion measurements, we used a deuterium exchange technique described in detail elsewhere [19]. We use now commonly this method in samples with short NMR relaxation time instead of the more standard NMR self-diffusion technique. Briefly, a sample initially saturated with water is placed in a tube and immersed in deuterium. The tube is placed in the NMR apparatus in order to monitor the concentration of water vs. time in the sample as deuterium is diffusing in and water diffusing out of the sample (deuterium is not detected by the NMR apparatus tuned to water). The curve is then analysed using standard analytical diffusion models. Compared to through-diffusion techniques using radioactive tracers, the experiment is relatively fast (of the order of 12 $24 \mathrm{~h}$ ) because diffusion is occurring in all directions and the sample is small (diameter and length of about $15 \mathrm{~mm}$ ). Beside the effective diffusion coefficient, one can also obtain the amount of non-connected porosity by analysing the NMR signal left at the end of the experiment (see [19] for an example).

The high pressure NMR cell is custom-build and entirely made of non-magnetic and nonconducting material (polyetherethercetone or PEEK). Such material gives a NMR signal at around $0.08 \mathrm{~ms}$ and is therefore not suited for detecting this range of relaxation times, corresponding mostly to hydroxyls in clay rich rock samples. It was designed for the 18 
$\mathrm{mm}$ probe, the maximum sample size is $9 \mathrm{~mm}$ in diameter and $20 \mathrm{~mm}$ in length (Figure 2). It can sustain up to 200 bar at $30^{\circ} \mathrm{C}$ and it has been tested up to $541 \mathrm{bar}$, at which pressure it will leak (but not break). The cell is connected to a $500 \mathrm{cc}$ single cylinder pump to vary the pressure from 20 up to 200 bar. With low porosity samples such as shales, dead volumes around the samples can represent $90 \%$ of the signal. Hence, a fine sand was introduced around the sample and in the tube above to reduce these dead volumes.



Figure 2: High pressure NMR cell (200 bar). The sample can be placed in the compartment at the left (in part 1 , dia. $9 \mathrm{~mm}$, length $20 \mathrm{~mm}$ ).

\subsection{Samples}

The investigated samples were collected from the Mississippian Barnett Shale, Fort Worth Basin (Texas-USA). We used both the source rock and the associated kerogen samples at different thermal maturity stages in order to test the NMR responses of both pseudo-dry and methane-filled materials. The organic matter properties from the selected samples were previously determined by Rock-Eval 6 analysis and organic petrography following the analytical procedures described in Romero-Sarmiento et al. [20]. The acquired Rock-Eval 6 parameters from both the initial source rock samples and their corresponding kerogens are also shown in Table 2. The kerogen samples were isolated using a non-oxidizing acid treatment to dissolve the mineral matrix under a nitrogen atmosphere following the standard procedure described in Durand and Nicaise [21]. Three different maturity level were available as follow: the immature San Saba sample, the oil-mature Mesquite 1 sample and the gas-mature Blakely 1 sample (Table 2; see also Figure 2 in Romero-Sarmiento et al., [20]). Photomicrographs of macerals from both the oil and gas mature samples indicate the presence of bitumen filling natural cavities [20]. Furthermore, elemental analyses were here performed twice on isolated kerogen samples by SGS Laboratories (France) following the standard procedures to determinate the $\mathrm{C}, \mathrm{H}$, $\mathrm{O}, \mathrm{N}, \mathrm{Fe}$ and $\mathrm{S}$ content (Table 3 ). 
Table 2: Characteristics of the 3 kerogens analyzed

\begin{tabular}{|c|c|ccccc|}
\hline \multicolumn{2}{|c|}{ Barnett sample } & \multicolumn{5}{c|}{ Source rock sample } \\
\hline County & Maturity & $\mathbf{S}_{\mathbf{2}}(\mathbf{m g} / \mathbf{g})$ & $\mathbf{T}_{\mathbf{m a x}}\left({ }^{\circ} \mathbf{C}\right)$ & $\mathbf{T O C}(\mathbf{w t} \%)$ & $\mathbf{H I}(\mathbf{m g} / \mathbf{g T O C})$ & OI(mg/gTOC) \\
\hline San Saba 1 & Immature & 48,74 & 415 & 11,6 & 418 & 14 \\
Mesquite 1 & Oil mature & 5,93 & 451 & 3,45 & 172 & 0 \\
Blakely 1 & Gas mature & 0,41 & $>500$ & 2,82 & 15 & 1 \\
\hline \multicolumn{2}{|c|}{ Barnett sample } & \multicolumn{5}{c|}{ Isolated kerogen sample } \\
\hline County & Maturity & $\mathbf{S}_{\mathbf{2}}(\mathbf{m g} / \mathbf{g})$ & $\mathbf{T}_{\mathbf{m a x}}\left({ }^{\circ} \mathbf{C}\right)$ & $\mathbf{T O C}(\mathbf{w t} \%)$ & $\mathbf{H I}(\mathbf{m g} / \mathbf{g T O C})$ & OI(mg/gTOC) \\
\hline San Saba 1 & Immature & 11,64 & 416 & 65,57 & 418 & 18 \\
Mesquite 1 & Oil mature & 2,23 & 441 & 51,22 & 137 & 4 \\
Blakely 1 & Gas mature & 1,58 & 466 & 57,57 & 11 & 3 \\
\hline
\end{tabular}

Table 3: Elemental composition of the investigated Barnett kerogens.

\begin{tabular}{|c|c|cccccc|}
\hline \multicolumn{2}{|c|}{ Barnett sample } & \multicolumn{6}{|c|}{ Isolated kerogen sample } \\
\hline County & Maturity & $\begin{array}{c}\text { C } \\
\text { (wt.\%) }\end{array}$ & $\begin{array}{c}\text { H } \\
\text { (wt.\%) }\end{array}$ & $\begin{array}{c}\text { O } \\
\text { (wt.\%) }\end{array}$ & $\begin{array}{c}\text { N } \\
\text { (wt.\%) }\end{array}$ & $\begin{array}{c}\text { S } \\
\text { (wt.\%) }\end{array}$ & $\begin{array}{c}\text { Fe } \\
\text { (wt.\%) }\end{array}$ \\
\hline San Saba 1 & Immature & 65,65 & 5,92 & 9,94 & 2,97 & 8,91 & 3,95 \\
Mesquite 1 & Oil mature & 46,20 & 3,34 & 6,89 & 1,32 & 22,40 & 17,58 \\
Blakely 1 & Gas mature & 50,15 & 2,29 & 5,67 & 1,18 & 21,88 & 15,02 \\
\hline
\end{tabular}

The results on a mini-plug $(\mathrm{D} \approx \mathrm{L} \approx 15 \mathrm{~mm})$ of shale (labelled $\mathrm{RM} 9$, Horn River) are also presented. The sample originates from a gas zone and has a total organic content of about $7 \%$. No particular cleaning was performed. To ensure full water saturation, the sample was kept under high static pressure during several days. To dry the sample, a standard protocol was applied (oven dry at $60^{\circ} \mathrm{C}$ until a stable mass is reached). Since no particular care was taken to keep the sample in dry air, this is only a pseudo dry state since water vapour can adsorb in the smallest pores, in equilibrium with the ambient humidity at laboratory temperature, a well-known effect. This is further discussed below. NMR porosity is $7.1 \%$ and gas permeability is $2 \mathrm{nD}$ in the dry state, value measured using a steady state technique [22]. 


\section{RESULTS}

The instrument used for this study is able to detect all protons present in the samples. For pseudo-dry samples (i.e. samples at equilibrium with the ambient humidity), we are able to detect hydroxyls part of the clay structure and protons from the kerogen. For water or methane saturated samples, the signal will be dominated by water or methane and it may be difficult to detect at the same time weak signal originating from kerogen. Hence, in order to evidence the signature of each element, we studied separately the samples in dry or saturated conditions: isolated dry kerogen alone, dry samples with the same kerogen, kerogen saturated with methane, dry shale sample, water and methane saturated shale sample.

\subsection{Kerogen signature}

The signal from 3 different dry kerogens isolated from core samples is shown in Figure 3. $T_{2}$ values are around $0.1 \mathrm{~ms}$ and below in the gas window. When the organic matter is immature, the $T_{1} / T_{2}$ tends to be smaller $(\sim 50)$ than in the oil and $\left(T_{1} / T_{2} \sim 250\right)$ gas windows $\left(\mathrm{T}_{1} / \mathrm{T}_{2} \sim 180\right)$. This observation is consistent with the fact that the mobility of protons is expected to be larger for immature kerogen. However, a gradual increase of the $\mathrm{T}_{1} / \mathrm{T}_{2}$ ratio as a function of maturity is not observed and we find a higher ratio in the oil window $(\sim 250)$ than the gas window $(\sim 180)$. In the gas window, there is also a secondary peak at $T_{2} \sim 0.2 \mathrm{~ms}$ which may be due to bitumen as observed on thin sections [20]. Given the chemical complexity of these kerogens, expressing the molecular mobility of protons using a simple $T_{1} / T_{2}$ ratio is probably a strong oversimplification. This behaviour would need more samples and detailed studies to be clarified, especially with respect to the bitumen content which has not been quantified in previous studies [20]. Another issue may come from the $2 \mathrm{D}$ Laplace inversion techniques to calculate $\mathrm{T}_{1}-\mathrm{T}_{2}$ maps. Indeed, magnetization from solid like proton interactions may decay as Gaussian functions [23], whereas exponential functions are used. As pointed out also by other authors [11], 2D techniques using Gaussian decays are not available but the use of exponentials may not have a large impact on the results.

From FID data using Gaussian decays (in a similar way as for smectites [3]), we can also estimate the total amount of hydrogen present in the samples: from immature, oil and gaskerogens, we obtain respectively $59 \mathrm{mg} / \mathrm{g}, 30 \mathrm{mg} / \mathrm{g}$ and $21 \mathrm{mg} / \mathrm{g}$ of hydrogen per gram of dry material. This is in agreement with the general trend that hydrogen content decreases with maturity as also indicated by Rock-Eval hydrogen index measurements expressed in units of $\mathrm{mg}$ of hydrocarbon per $\mathrm{g}$ of total organic content (Table 2). It is calculated as the amplitude of the so-called RockEval S2 peak divided by the total organic content (TOC). As expected, a relationship exist between these two quantities (Figure 4); the NMR measurements are also in good agreement with elemental analysis yielding the hydrogen content (Table 3 ). 

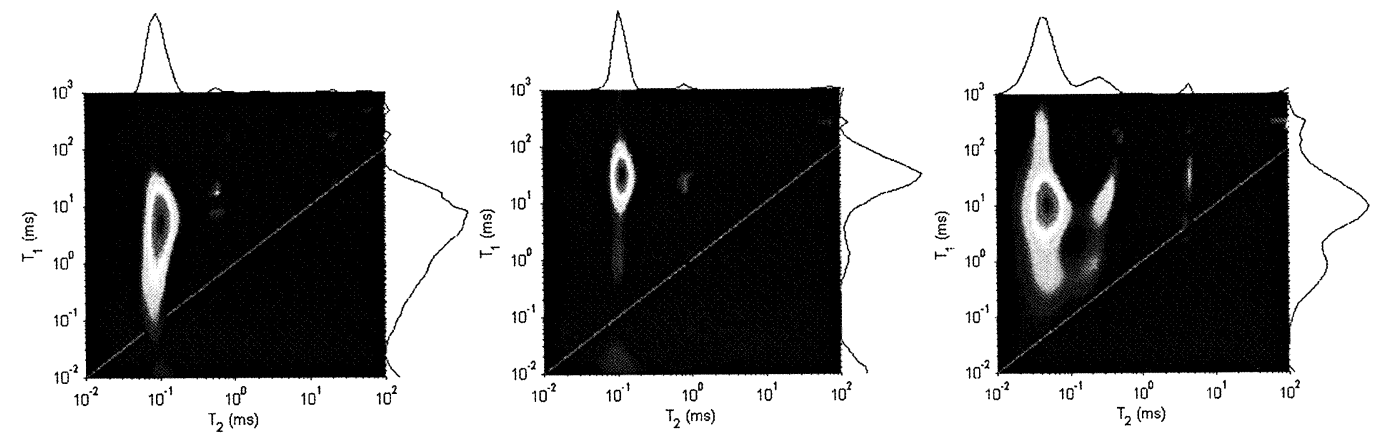

Figure 3: $T_{1}-T_{2}$ maps on three types of kerogen isolated from shale samples. For left to right: immature $\left(\mathrm{T}_{1} / \mathrm{T}_{2} \sim 50\right)$, oil $\left(\mathrm{T}_{1} / \mathrm{T}_{2} \sim 250\right)$ and gas $\left(\mathrm{T}_{1} / \mathrm{T}_{2} \sim 180\right)$ window.

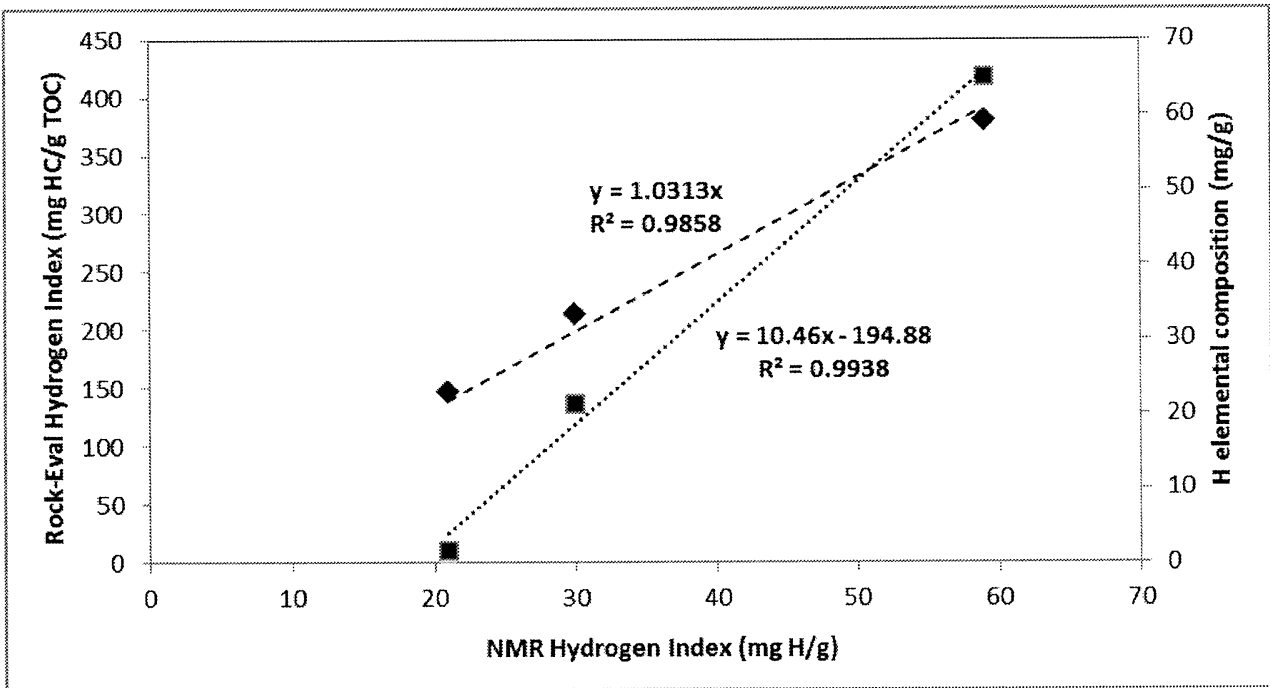

Figure 4: Relationship between the hydrogen content of 3 kerogens measured by NMR and the RockEval hydrogen index (left) and the elemental analysis (right).

Analyzing now the core samples from which the organic matter was isolated (only two of them were available, Figure 5), we first observe a large signal in the range $0.01<\mathrm{T}_{2}<0.1$ $\mathrm{ms}$, at the limit of $\mathrm{T}_{2}$ resolution. It is also spread over a wide $\mathrm{T}_{1}$ range (and easily resolved) and this is typical of hydroxyls from the clay structure. In the oil window, kerogen appears as a secondary peak located at $\mathrm{T}_{2} \sim 0.5 \mathrm{~ms}$ and $\mathrm{T}_{1} \sim 100 \mathrm{~ms}$, in relative agreement with its location when isolated from the samples $\left(\mathrm{T}_{2} \sim 0.1 \mathrm{~ms}\right.$ and $\left.\mathrm{T}_{1} \sim 50 \mathrm{~ms}\right)$. In the gas window, the kerogen signal cannot be identified because it overlaps with the hydroxyl signal. 

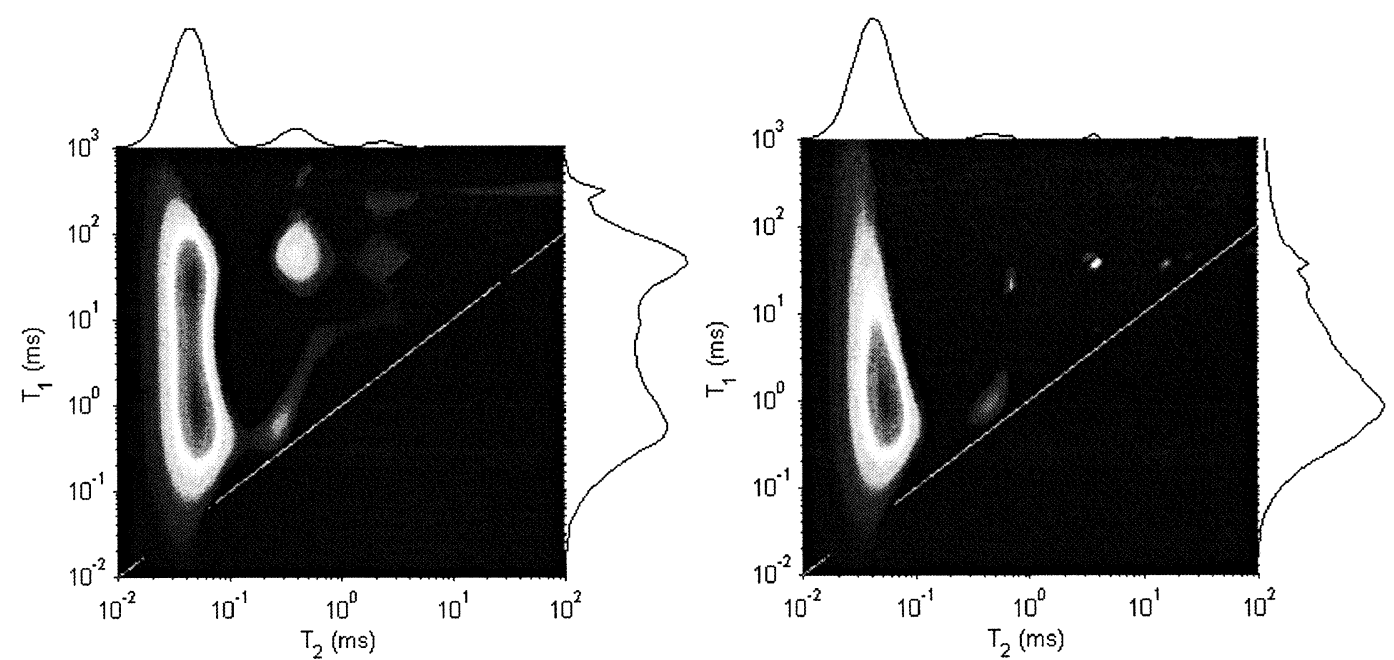

Figure 5: $T_{1}-T_{2}$ maps on two dry shale samples from which organic matter was extracted. Left: oil window; right: gas window. In the gas window, organic matter cannot be distinguished.
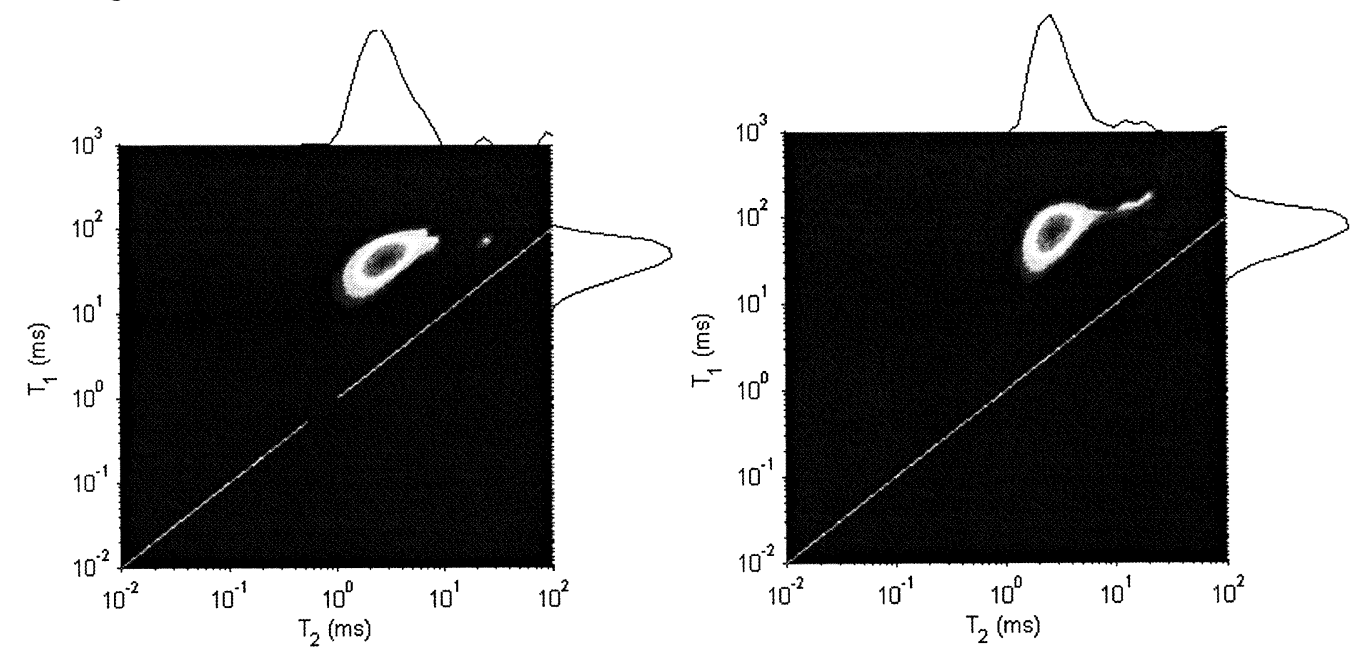

Figure 6: Methane saturated organic matter in the gas window. Left: 100 bar $\left(\mathrm{T}_{1} / \mathrm{T}_{2} \sim 15\right)$; right: 200 bar $\left(\mathrm{T}_{1} / \mathrm{T}_{2} \sim 20\right)$.

Finally, we also identified the signal of methane saturated kerogen (Figure 6). Because kerogen is a powder and no more compacted in the sample, the signature identified here includes inter and intra-granular porosity. Contrary to water saturated situations, the diffusivity of methane is such that there is an exchange between inter and intra granular pores and therefore, the two porosity compartments cannot be distinguished. The relaxation time $T_{2}$ should then be interpreted as proportional to the total volume divided by the total surface; the surface is driven by the internal surface inside the grains but the 
volume is driven by the inter-granular porosity. Hence, we expect that the true signature of methane in kerogens in the sample be shifted to lower $T_{2}$ values due to smaller volumes in the absence of inter-granular porosity. The $T_{1} / T_{2}$ ratio (between 15 and 20 depending on pressure) is typical of gas interactions with a solid, as will be seen also later. Recently, the method for isolating kerogens has been criticized because it could yield to a collapse of the porosity [24]. Eventhough this may occur for the samples analysed here, there is a significant nano and micro-porosity preserved as shown by nitrogen adsorption measurements [20].

\subsection{Shale samples}

For this sample, high pressure mercury injection (HPMI) performed on a nearby sample reveal very small pore entry sizes (Figure 8). Clearly, in this case, the limit of resolution is reached and the porosity from the HPMI experiment was only half of the NMR porosity.

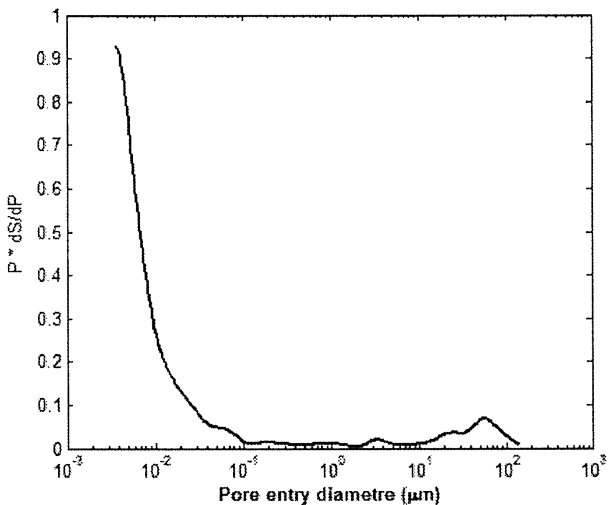

Figure 7: Pore entry size distribution from mercury injection experiments representing reservoir sample RM9. The limit of resolution is reached.

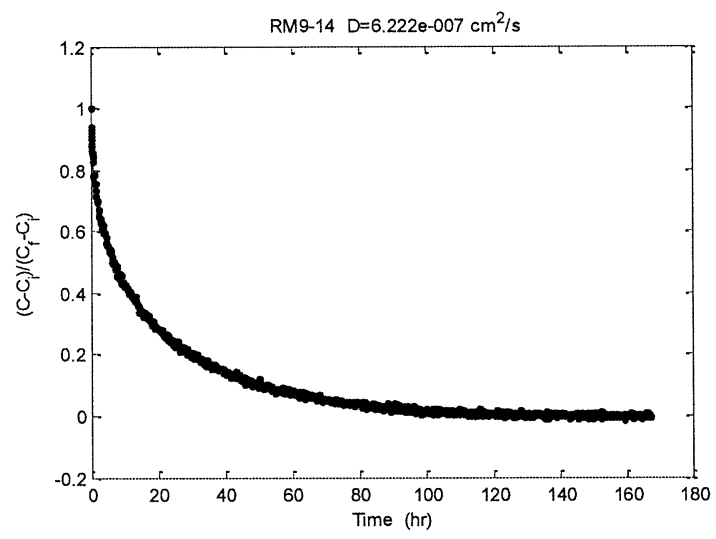

Figure 8: Deuterium diffusion experiment for reservoir sample RM9 (d=15mm, $L=15 \mathrm{~mm}$ ) performed at $30^{\circ} \mathrm{C}$. Data (dots) and fit (line).

Despite the very small pore size distribution, the deuterium exchange experiment reveal a very good connectivity of the pore network. The curve shown in Figure 8 represents the average concentration of water (w.r.t. deuterium) as a function of time while deuterium is diffusing inside the core and water outside. Unconnected porosity would show up as a residual signal at the end of the experiment, but this was not observed. Experimental data can be matched very well with a homogeneous diffusion model. We find an effective diffusion coefficient $D_{\text {eff }}=0.6210^{-6} \mathrm{~cm}^{2} / \mathrm{s}$. Defining a tortuosity $\tau$ as $D_{m} / D_{\text {eff }}$ (the diffusion coefficient of free water $D_{m}=2.6010^{-5} \mathrm{~cm}^{2} / \mathrm{s}$ at $30^{\circ} \mathrm{C}$ ), we obtain 
$\tau=41.8$. In general, the diffusion coefficients can also be compared to a standard Archie relationship according to:

$$
\frac{D_{e f f}}{D_{m}}=\Phi^{m-1}
$$

where $\mathrm{m}$ is the Archie's cementation exponent. We obtain $\mathrm{m}=2.45$, a value within the expected range.

The absolute value of diffusivity is also of interest. Indeed, we can calculate a typical diffusion length, $(6 \mathrm{Dt})^{1 / 2}$ at time $\mathrm{t}=1 \mathrm{~ms}$ and we obtain about $800 \mathrm{~nm}$. We chose $1 \mathrm{~ms}$ because it is the typical life time of the magnetization as given by $\mathrm{T}_{2}$ distribution. Hence, most of the pores explored by the molecules during diffusion according to the model explained above (equation 1) will be averaged to a single relaxation time. This is a strong evidence of a strong diffusive pore coupling effect. The consequence is that the $\mathrm{T}_{2}$ distribution measured in shales does not represent a pore size distribution for pore sizes smaller than about 1 micron. Also the classical method for deducing capillary bound water using a cut-off is not applicable for shales, and comparison of NMR distribution with other measurements of pore size should be made very carefully.

The RM9 shale sample was also analyzed at different saturation states: dry, water and methane saturated. For the dry sample, the $T_{1}-T_{2}$ map is dominated by the hydroxyl signal with $T_{2}$ less than $0.1 \mathrm{~ms}$ (Figure 9) and a wide range of $\mathrm{T}_{1}$ values. Between 0.1 and $1 \mathrm{~ms}$, there is some residual water, mainly distinguishable in the $T_{2}$ distribution. When saturated with water, we can clearly distinguish the water signal with $\mathrm{T}_{1} / \mathrm{T}_{2} \sim 2$. To calculate porosity, we took only this signal into account. The water $\mathrm{T}_{2}$ distribution has essentially two modes, due to an heterogeneity clearly visible in micro-tomography images (not shown, a thin layer of kerogen in the longitudinal direction). For the methane saturated case (Figure 10), the situation is very different and we have a large contrast between $T_{1}$ and $T_{2}$, as already expected and observed in kerogen. For this experiment, the large peak $\left(T_{2} \sim 60 \mathrm{~ms}\right.$ and $\left.T_{1} \sim 1000 \mathrm{~ms}\right)$ represents methane in the sand around the sample, and the small peak $\left(\mathrm{T}_{2} \sim 10 \mathrm{~ms}\right.$ and $\left.\mathrm{T}_{1} \sim 1000 \mathrm{~ms}\right)$ methane in the shale sample. Indeed, even though the shale total volume is dominant, its small porosity (7\%) is such that the pore volume in the sand around and at the top of the sample is dominant. 

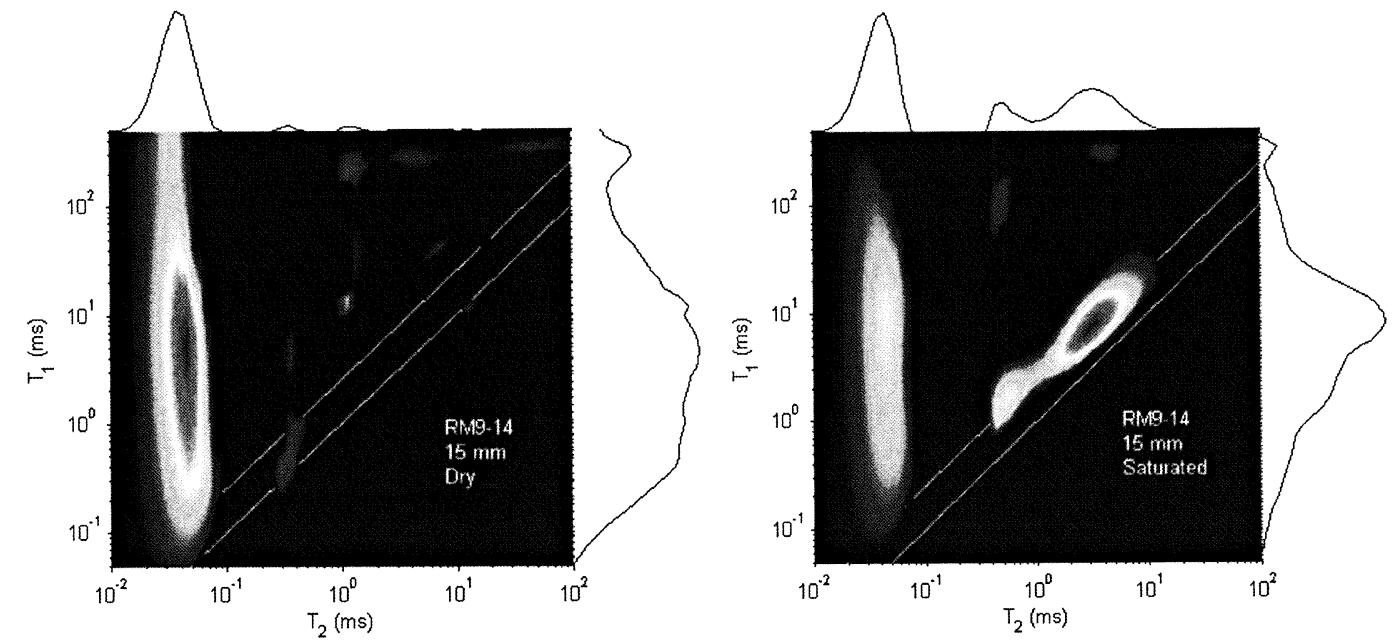

Figure 9: $T_{1}-T_{2}$ maps on $15 \mathrm{~mm}$ diameter miniplugs in the dry and water saturated state. The short $T_{2}$ signal with a large range of $T_{1}$ represents hydroxyls and organic matter. The two lines indicate $T_{1} / T_{2}=1$ and $T_{1} / T_{2}=2$.



Figure 10: $T_{1}-T_{2}$ maps for methane at 200 bar for sample RM9 (small peak at $T_{2}=10 \mathrm{~ms}$ and $\mathrm{T}_{1}=1000 \mathrm{~ms}$ ). The large peak corresponds to the $80 \mathrm{um}$ quartz sand around the sample. 




Figure 11: Fluid or proton typing using $T_{1}-T_{2}$ maps

\subsection{Synthesis : $\mathbf{T}_{1}-\mathrm{T}_{2}$ fluid mapping}

For shale samples, we see that the $T_{1}-T_{2}$ map is a very efficient way to separate the contributions from the different compartments containing hydrogen molecules. The sketch in Figure 11 summarize the results obtained in this study. The $\mathrm{T}_{2}$ axis represents a pore size after scaling with the surface relaxivity. For a given sample, the distribution of relaxation times may not represent a distribution of pore sizes due to diffusive exchanges already mentioned; but if two samples have a different average pore size, the average relaxation time $T_{2}$ for these two samples will be different. We have two limits on the $T_{2}$ axis: (i) the lowest value that can be reached when water interact with the surface (relaxation time $\mathrm{T}_{2 \mathrm{~S}}$ of water molecules that would be permanently at the solid surface) and (ii) the resolution limit linked to the instrument used; it can be evaluated by taking the inter-echo time; for example in our case and depending on the probe $0.06 \mathrm{~ms}$. The $\mathrm{T}_{1}$ axis represents roughly the proton rotational mobility: for large $T_{1} / T_{2}$ ratio, the mobility is small; for solid protons, it also corresponds to reduced molecular mobility.

The different protons in the $T_{1}-T_{2}$ map can be associated with the following origins: 
- Hydroxyls: $\mathrm{OH}$ part of the clay structure or at the edges of clay platelets; this signal is always at the limit of resolution, below $0.1 \mathrm{~ms}$. It can only be detected with appropriate NMR instruments,

- Protons part of the kerogen: depending on the maturity, they can overlap with hydroxyls. They can be best detected in dry samples since their hydrogen index is quite low compared to water,

- Water: this signal is typically located on or close to the line $T_{1} / T_{2} \sim 2$ even for very small pore sizes such as interlayer space in clays,

- Methane: when considering $T_{2}$ only, this signal can overlap with the water signal, as noted by other authors [25]. However when considering $T_{1}$, it can easily be separated because $T_{1} / T_{2} \sim 10$. Such ratio is consistent with other measurements [17] and depend slightly on pressure. Adsorbed methane has no specific signature because it is in fast exchange with free methane.

We did not consider yet the signature of oil. With light oil, the $T_{1} / T_{2}$ ratio is slightly but significantly higher than 2 due a specific interaction with kerogen or bitumen [10]. For heavy oil or bitumen, it may increase largely [6].

We believe that the proposed $T_{1}-T_{2}$ mapping can be applied to many systems. However, more studies are required to characterize the spreading of each population in such $T_{1}-T_{2}$ map, especially for kerogen. The kerogen signature also depends on frequency; indeed, $T_{1}$ depends on frequency as opposed to $T_{2}$ (see equations 2). Hence, $T_{1}-T_{2}$ maps established at $2 \mathrm{MHz}$ using standard low-field NMR instrument (and not at $23.7 \mathrm{MHz}$ as in this study) will be slightly different with smaller $T_{1} / T_{2}$ ratios.

\section{CONCLUSION}

We evidenced the signature of the 4 protons populations present in shale samples in a $T_{1}$ $\mathrm{T}_{2}$ map: hydroxyls from the clay structure, protons from the kerogens, water and methane at various pressure. These signatures have been determined on isolated kerogens, and shale samples at different saturation states. In a $T_{1}-T_{2}$ map, these signatures do not overlap, except for kerogen with high maturity. The position of these signatures is qualitatively well understood from NMR relaxation theory as well as existing work on methane in porous media. From diffusion measurements on a shale sample, we also conclude that the typical diffusion length for water is about $800 \mathrm{~nm}$, It means that the relaxation times for pore smaller than this length are averaged to a single relaxation time and that the relaxation time distribution does not indicate the true pore size distribution.

\section{AKNOWLEDGEMENT}

We thank ExxonMobil Upstream Research Co. for allowing us to use some results of an unpublished study. 


\section{REFERENCES}

[1] Josh M, Esteban L, Piane CD, Sarout J, Dewhurst DN, Clennell MB. Laboratory characterisation of shale properties. J Pet Sci Eng 2012;88-89:107-24.

[2] Loucks RG, Reed RM, Ruppel SC, Jarvie DM. Morphology, Genesis, and Distribution of Nanometer-Scale Pores in Siliceous Mudstones of the Mississippian Barnett Shale. J Sediment Res 2009;79:848-61.

[3] Fleury M, Kohler E, Norrant F, Gautier S, M'Hamdi J, Barré L. Characterization and Quantification of Water in Smectites with Low-Field NMR. J Phys Chem C 2013;117:4551-60.

[4] Sigal RF, Odusina E. Laboratory NMR measurements on methane saturated Barnett shale samples. Petrophysics 2011;52:32-49.

[5] Washburn KE, Birdwell JE. Updated methodology for nuclear magnetic resonance characterization of shales. J Magn Reson 2013;233:17-28.

[6] Rylander E, Singer PM, Jiang T, Lewis R, Mclin R, Sinclair S. NMR T 2 Distributions in the Eagle Ford Shale : Reflections on Pore Size. Proceeding Soc. Pet. Eng. SPE 164554, 2013.

[7] Kausik R, Minh C, Zielinski L. Characterization of Gas Dynamics in Kerogen Nanopores by NMR. Proceeding Soc. Pet. Eng. SPE 147198, 2011.

[8] Hürlimann MD, Venkataramanan L. Quantitative measurement of twodimensional distribution functions of diffusion and relaxation in grossly inhomogeneous fields. J Magn Reson 2002;157:31-42.

[9] Daigle H, Johnson A, Gips JP, Sharma M. Porosity Evaluation of Shales Using NMR Secular Relaxation. Proc. 2nd Unconv. Resour. Technol. Conf. SPE $1905272,2014$.

[10] Korb J, Nicot B, Bubici S, Ferrante G. Dynamics and Wettability of Oil and Water in Oil Shales. J Phys Chem C 2014;118:23212-8.

[11] Birdwell JE, Washburn KE. Multivariate Analysis Relating Oil Shale Geochemical Properties to NMR Relaxometry. Energy \& Fuels 2015;29:2234-43.

[12] Korringa J, Seevers D, Torrey H. Theory of Spin Pumping and Relaxation in Systems with a Low Concentration of Electron Spin Resonance Centers. Phys Rev 1962;127:1143-50.

[13] Fleury M, Soualem J. Quantitative analysis of diffusional pore coupling from T2store-T2 NMR experiments. J Colloid Interface Sci 2009;336:250-9.

[14] Abragam A. Principles of Nuclear Magnetism. 1961.

[15] Weglarz W. Observation of Coupling Across the Ice Water Interface by 2D Time Domain NMR. J Magn Reson 1997;485:484-5.

[16] Oosting PH, Trappeniers NJ. Proton-Spin-Lattice Relaxation and Self-diffusion in methanes III. Interpretation of proton-spin-lattice relaxation experiments. Physica 1971;51:395-417.

[17] Straley C. An experimental investigation of methane in rock materials. SPWLA 38th Annu. Logging Symp., 1997.

[18] Riehl JW. NMR Relaxation of Adsorbed Gases: Methane on Graphite. J Chem Phys 1972;57:2199. 
[19] Berne P, Bachaud P, Fleury M. Diffusion Properties of Carbonated Caprocks from the Paris Basin. Oil Gas Sci Technol - Rev l'Institut Français Du Pétrole 2009;65:473-84.

[20] Romero-Sarmiento M-F, Rouzaud J-N, Bernard S, Deldicque D, Thomas M, Littke R. Evolution of Barnett Shale organic carbon structure and nanostructure with increasing maturation. Org Geochem 2014;71:7-16.

[21] Durand B, Nicaise G. Procedures for kerogen isolation. Kerogen insoluble Org. matter from Sediment. rocks, Editions Technip, Paris; 1980, p. 35-53.

[22] Boulin PF, Bretonnier P, Gland N, Lombard JM. Contribution of the Steady State Method to Water Permeability Measurement in Very Low Permeability Porous Media. Oil Gas Sci Technol - Rev d'IFP Energies Nouv 2012;67:387-401.

[23] Washburn KE, Anderssen E, Vogt SJ, Seymour JD, Birdwell JE, Kirkland CM, et al. Simultaneous Gaussian and exponential inversion for improved analysis of shales by NMR relaxometry. J Magn Reson 2015;250:7-16.

[24] Suleimenova A, Bake KD, Ozkan A, Valenza JJ, Kleinberg RL, Burnham AK, et al. Acid demineralization with critical point drying: A method for kerogen isolation that preserves microstructure. Fuel 2014;135:492-7.

[25] Tinni A, Odusina E, Hughes B, Sulucarnain I, Sondergeld C, Rai C. NMR Response of Brine, Oil, and Methane in Organic Rich Shales. Proceeding Soc. Pet. Eng. SPE 168971, 2014. 